\title{
Personal characteristics of post-traumatic stress disorders
}

\author{
Fayzura Semenova, Svetlana Bostanova*, Maryam Tetueva, and Dianna Akbayeva \\ Umar Aliev Karachai-Cherkess State University (KCSU), 369202, Karachayevsk, Russia
}

\begin{abstract}
In modern conditions, achieving high results in sports for professional athletes is associated with enormous physical and mental stress. This situation is aggravated by the fierce competition in the sports arena, which requires the manifestation of motor abilities at the level of the limit of human capabilities, provoking a constant stressful atmosphere and placing increased demands on the personal and professional qualities of modern athletes. The scientific article discusses the dependence of personal characteristics and features of the manifestation of post-traumatic stress disorders in professional athletes; sports competitions have a strong impact on the emotional status of an athlete. The main stress factor in the sports activity of an athlete is considered to be traumatization, i.e. getting physical and psychological injuries, which affects not only the sports career, but also leads to serious post-traumatic disorders. We assume that in the body of a professional athlete who is in a stressful environment for a long time (training, competitions), psychosomatic reactions occur that cause posttraumatic stress disorder, and also that the features of the course of this disorder depend on the personal characteristics of athletes. Post-traumatic stress disorder is a severe mental condition that occurs as a result of single or repeated events that have a super - powerful negative impact on the individual's psyche.
\end{abstract}

\section{Introduction}

The problem of stress tolerance has been studied and continues to be studied by foreign and domestic researchers. We have analyzed the works of scientists on this issue (V. Ya. Apchel, J. Grinberg, L. A. Kitaev-Smyk, B. V. Ovchinnikov, G. Selye, R. A. Tigranyan, Holmes, Izard, E. T. Berezkin, V. A. Chursinov and others). Researchers note a significant compensating ability of the person's personality in general, and the athlete, in particular, in a particular stressful situation. In the sports professional activity of an athlete at all stages of a sports career, there are new opportunities and new problems, events that have a strong impact on the athlete's psyche. Stress is the body's response to the effects of various stressors.

According to $\mathrm{Yu}$. V. Shcherbatykh, all stress associated with physical activity can be divided into a group of short-term effects and a group of long-term effects on the body [1].

Let's briefly consider them. The group with short-term effects includes: the first is stressors that cause fear associated with the performance of a previously traumatic sport; the

\footnotetext{
* Corresponding author: bostanova14@mail.ru
} 
second is stressors that cause physical discomfort, which is manifested by fatigue, pain and a constant feeling of ill-health; the third is stressors that are associated with speed, i.e., for example, unreasonably high expectations of high results obtained; the fourth is an objective stressor (for example, an unfavorable start, errors in sports equipment, etc.). The group with long-term effects on the body includes: stress factors associated with risks and dangers (skills, ski jumping, mountaineering, racing, hockey); stressors associated with long-term exercise (long-term exercise against the background of physical and mental fatigue); sources of stress associated with struggle (long-term competition); stressors associated with isolation (separation from family and family members in the game); stressors are internal and external environmental factors that cause tension or stress [1].

Sports activity as an activity that requires exertion of physical and psychological qualities and properties is associated with many stressful situations. For professional athletes, sport acts as a stress, is a stressor. The obligation to take first or second places, to participate in large-scale competitions, to speak for the country for athletes is a factor that causes serious effects on the emotional background [2].

Sport is not only a physiological, physical, but also a psychological burden. The athlete's psyche gets a huge stress load. Therefore, it is important to know what mechanisms should be used to reduce stress loads. For an athlete, sports can be both a profession and an everyday activity that determines his lifestyle.

During the competition, the athlete, in the absence of absolute confidence that all the internal mechanisms that contribute to ensuring high results will work best at the right time, may have an internal uncertainty factor: physiological "fluctuations", a violation of the functional state of the body and various subjective obstacles.

The main task of athletes is to reproduce the best results obtained during training. In sports without obvious external obstacles, first of all, there is a stressful factor of internal uncertainty. These are mainly sports: athletics, gymnastics, weightlifting, and others $[1 ; 2$; 3].

The source of the pressure of external uncertainty that causes stress is various factors, such as: the level of sports competitions, the characteristics of opponents and competitors, the current psychological and physical status, etc.

Depending on the above factors, the pressure of external uncertainty can be divided into several stages: in the first stage, there is anxiety for the mobilization of the initial forces of the body [4]. The athlete begins to adapt to this situation, but at the same time the body's resistance decreases. In some athletes, sudden, for example, "stress agents" can cause shock, severe stress. The second stage is characterized by the body's reaction to stress; it is called the resistance stage, i.e., the resistance stage. There is a general adaptation syndrome, which is characterized by the inclusion of protective mechanisms and all internal resources $[5 ; 6]$. The third stage is the stage of exhaustion, which occurs with intense and prolonged exposure to a very strong stimulus. With a weak stimulus, there is a functional weakness of the adaptive mechanisms. This stage (the stage of exhaustion) also occurs naturally, as a response to stress. The two previous stages are also a response to stress, which is considered the physiological norm $[6 ; 7]$.

Individual sports can be characterized by stressors with an internal meaning; group sports, in which intra-group interaction is significant, are characterized by the manifestation of stressors with an external meaning. The appearance of external and internal stress factors in most cases is influenced by the personal characteristics of the athlete, as well as the social environment, and not the requirements and characteristics of sports activities $[7 ; 8 ; 9]$.

Individual characteristics of the athlete's personality are included in the structure of his sports professional activity as internal conditions or internal means that directly or indirectly affect the characteristics of the pressure of external uncertainty, determining the success of performances at competitions. 
Sports activity and individual mental qualities of an athlete are closely related categories that mutually determine each other. This effect is caused by the following features: the competitive nature of the fight, the establishment of a winning record by an opponent or the desire to win; the maximum load on all physical, mental and mental abilities, during the competition, necessary to achieve the planned results; the nature of physical activity: constant, long-term, continuous, which determines the lifestyle and activities of the athlete $[7 ; 8 ; 9]$.

Stress causes a significant loss of energy in the athlete's body and creates such physiological conditions that the body's ability to resist stress decreases. When an athlete experiences intense stress, the following symptoms are most often manifested: nervousness, aggressiveness, anxiety and anxiety, fatigue, irritability, as well as physiological (insomnia, loss of appetite, etc.). The researchers note that stress does not always have a negative impact on the body: with moderate stress, the mind and body of a person function most effectively and make the body ready for an optimal mode of work. The achievement of the set goals is ensured without exhausting the vital forces of the body, as well as the ability to get out of a destructive state with the least losses [10].

A high level of stress can remain a positive factor, only for a very short time, stimulating interest in life, making you think quickly and act more intensely, feel important, have a purpose in life, and acutely comprehend the value of health $[11 ; 12]$.

An athlete who has not learned to manage his psyche and has been under severe stress for a long time increases the likelihood of various diseases. The duration of stress also disrupts the body's immune system, which leads to an increased risk of neuropsychiatric diseases [13].

It should be noted that each athlete has its own optimal level of stress, and when the limits of the optimal level are passed, stress begins to deplete the energy of the body, leading to a violation not only of the normal functioning of the body, but also to a violation of the optimal activity and communication of a person $[14 ; 15]$.

Modern psychological science proceeds from the fact that any person can achieve great success in sports, achieve high results in a certain sport, but it is always necessary to correctly assess the challenges and risks, stress and post-stress reactions, understanding that sports are a strong stressful effect on the athlete's body.

\section{Materials and methods}

The experimental study involved 40 athletes aged 18 to 30 years. Sports qualification: 18 people with the First sports category, 12 people-candidates for Master of sports, 10 peoplemasters of Russia in sports.

To achieve the set goal and objectives of the study, the following psychodiagnostic methods were used:

1) The questionnaire of traumatic stress for the diagnosis of psychological consequences - PTSD (I. O. Kotenev);

2) Kettell's 16-factor questionnaire

Statistical data processing was performed using SPSS 17.0 software, Microsoft Office Excel; the criterion for the reliability of differences (U-Man-Whitney test), T-Student's test.

\section{Results}

When conducting the method "Questionnaire of traumatic stress", developed by I. O. Kotenev with respondents, the following results were obtained, presented in Figure 1 and in Table 1. 


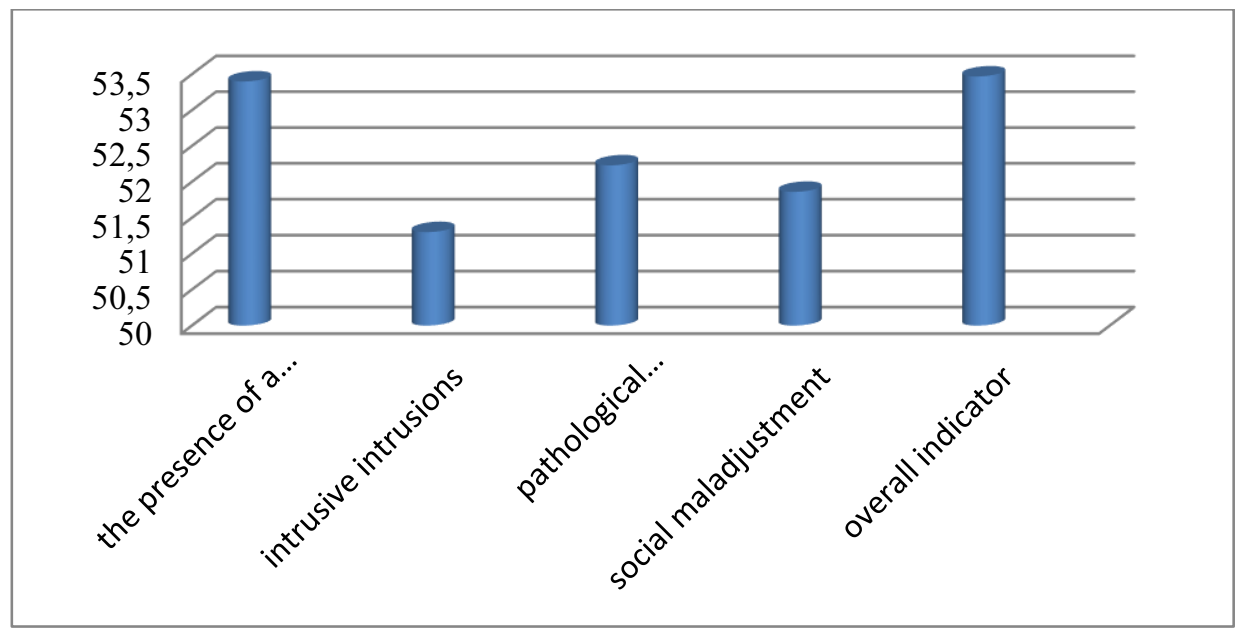

Fig. 1. Results of the study of the level of severity of post-traumatic stress disorder in athletes

Table 1. Results of the study of the level of severity of post-traumatic stress disorder in athletes

\begin{tabular}{|l|l|l|l|l|l|l|}
\hline $\begin{array}{l}\text { Name of } \\
\text { the scale }\end{array}$ & $\begin{array}{l}\text { The } \\
\text { presence } \\
\text { of a } \\
\text { traumatic } \\
\text { event }\end{array}$ & $\begin{array}{l}\text { Intrusive } \\
\text { intrusions }\end{array}$ & Avoidance & $\begin{array}{l}\text { Pathological } \\
\text { hyperactivity }\end{array}$ & $\begin{array}{l}\text { Social } \\
\text { maladjust } \\
\text { ment }\end{array}$ & $\begin{array}{l}\text { Overall } \\
\text { indicator } \\
\text { PTSD }\end{array}$ \\
\hline $\begin{array}{l}\text { The } \\
\text { Mann- } \\
\begin{array}{l}\text { Whitney } \\
\text { U-test }\end{array}\end{array}$ & -5.642 & -5.525 & -5.731 & -5.710 & -5.517 & -5.505 \\
\hline
\end{tabular}

The obtained empirical data showed (Figure 1) that all athletes have different scales that characterize the experience of severe mental trauma. Thus, on the "invasion" scale, $53.4 \mathrm{~b}$. were obtained, which indicates the presence of a secondary experience of traumatic events; on the "avoidance" scale $(51.3 \mathrm{~b}$.), this indicates that respondents try to avoid situations that resemble their traumatic situations, showing reluctance to conduct conversations on this topic; the scale "hyperactivity" (52.23 b.) indicates that this group of respondents is more hot-tempered, irritable and aggressive; on the scale "social maladaptation" (51.86 b) - these athletes often feel tired and irritated.

The statistical analysis carried out using the Mann-Whitney test (U-test), presented in Table 1, allows us to formulate an intermediate conclusion that all high-class athletes show different scales of the symptom of experiencing mental trauma.

To identify the personal characteristics of athletes with symptoms of post-traumatic stress disorder, we conducted a psychodiagnostic study using the 16-factor personality questionnaire by R. B. Kettell.

We subjected the obtained data to statistical processing using the Student's T-test. The results are shown in Figure 2 and Table 2. 


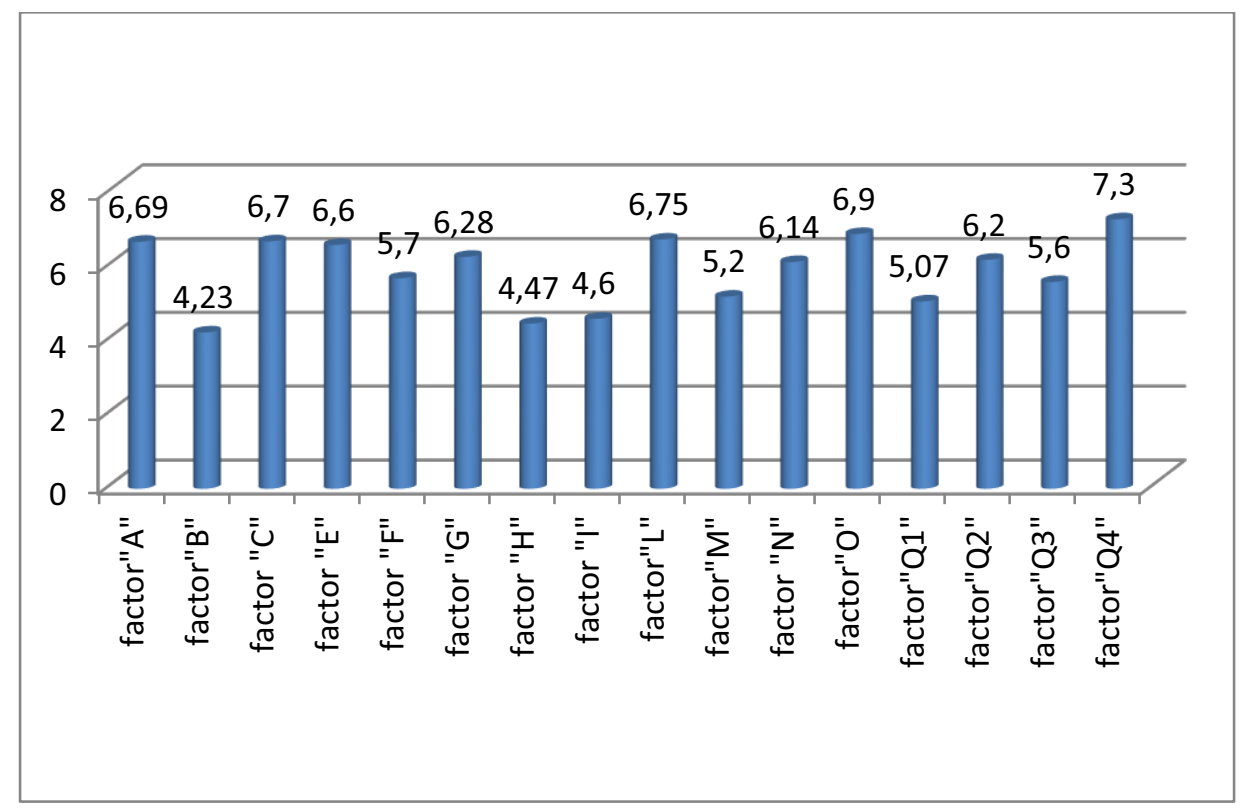

Fig. 2. Results of the study using the "16-factor personality questionnaire" by R. B. Kettell

Table 2. Results of the study of the level of severity of factors in athletes with PTSD.

\begin{tabular}{|c|c|c|c|}
\hline factors & athletes & Student's T-test & P \\
\hline A & 5.67 & 0.986 & - \\
\hline B & 4.16 & -1.510 & 0.01 \\
\hline C & 6.7 & $-3.187 * * *$ & - \\
\hline E & 5.4 & 1.015 & - \\
\hline F & 5.5 & 0.629 & - \\
\hline G & 6.27 & -1.173 & 0.001 \\
\hline H & 4.47 & -6.072 & - \\
\hline I & 4.5 & 1.658 & - \\
\hline L & 6.75 & $3.272 * * *$ & - \\
\hline M & 5.1 & -0.929 & 0.001 \\
\hline N & 6.12 & 0.083 & - \\
\hline O & 6.9 & $3.761 * * *$ & - \\
\hline Q1 & 5.07 & -0.773 & - \\
\hline Q2 & 6.1 & -0.407 & 0.001 \\
\hline Q3 & 5.5 & -0.957 & \\
\hline Q4 & 7.3 & $4.629 * * *$ & \\
\hline
\end{tabular}

Figure 2 shows that the "Strength of Self" factor (C) in athletes is $6.7 \mathrm{~b}$. According to this scale, it can be noted that athletes with symptoms of post-traumatic stress disorder exhibit such qualities as emotional immaturity, low ability to display skills of adequate behavior. The "timidity - determination" factor $(\mathrm{H}): 4.47 \mathrm{~b}$., These results suggest that the athletes of this subgroup have a low level of communication skills and the ability to adapt to the surrounding world; that in stressful situations, respondents of this subgroup can persistently violate social norms of behavior. According to the factor "trustfulness - suspicion" (L) is $6.75 \mathrm{~b}$., which indicates that these athletes are characterized by caution, a tendency to secrecy and concentration on unwanted experiences. According to the factor "the level of actual anxiety on current events" $(\mathrm{O})$, the respondents have $6.9 \mathrm{~b}$., which indicates that these athletes have a high level of anxiety, emotionality, sensitivity. According to the factor "level of total 
frustration tension" (Q4), the data obtained from the respondents was $7.3 \mathrm{~b}$. These athletes are characterized by a high level of frustration, the predominance of a tendency to irritability and fatigue, as well as the manifestation of "insubordination" in the behavior of the established rules.

Based on the empirical results of the conducted psychodiagnostic methods, we can state that high-class athletes show symptoms of post-traumatic stress disorder; that groups of respondents have symptoms of post-traumatic stress disorder characterized by special personal characteristics, which are highlighted in the factors according to the Kettell method. The most frequently manifested qualities are such qualities as: high caution, suspicion, high wary attention to others, fluctuation of the emotional background, manifested in mood instability, suspiciousness, anxiety.

\section{Discussion}

In psychological science, quite extensive research has been conducted on various aspects of this issue, but the problem requires further experimental development due to the urgency of the issue, since the problem of individual psychological characteristics of high-class athletes who are under constant psychological pressure is not fully developed.

For athletes, psychological work with stress becomes crucial, affecting the effectiveness of sports performances, well-being and mood. Researchers define psychological training as one of the main tasks in the professional training of athletes $[16 ; 17]$. The content and psychological preparation of athletes is determined by the following competencies: the ability to maintain stress at an optimal level, i.e. when it is useful for the active activity of the athlete; the ability to correctly assess the current situation, make responsible decisions and implement them; constantly engage in self-development: develop spiritual, physical and cognitive qualities.

It is important for athletes to be able to maintain a stable psychological stability to overcome adverse factors; each athlete should be able to assess the environment in a state of stress and should evaluate their behavior and try to respond adequately to events, master the techniques of voluntary muscle relaxation, breathing rules, switching attention and selfregulation $[17 ; 18]$.

Personal characteristics of athletes, as shown above, are determined by PTSD, influencing thoughts, ideas, ideas about yourself; emotional assessments (self-assessment, expectation of how others will evaluate you); aspirations and actions in accordance with the level of claims are also there. Undoubtedly, stress causes a change in the psychophysiological status, violating the unity of the biological, physiological and psychological qualities of the athlete: appearance (habitus); physiological activity of internal organs (heart, liver, kidneys); features of the hormonal balance; features of the nervous system; the main features of temperament.

The analysis of literature sources shows that athletes of various sports have common personal characteristics that manifest themselves in the course of PTSD and, in turn, make certain requirements for the psychological characteristics of the athletes ' personality. Highclass athletes are characterized by such qualities as discipline, a high level of will, responsibility, and the desire for leadership.

\section{Conclusions}

Based on the conducted research, we can draw the following conclusions:

- the results obtained indicate that high-class athletes have a manifestation of experiences of traumatic events, aggression; they are irritable and short-tempered; 
- it was revealed that athletes with symptoms of post-traumatic stress disorder are characterized by the following personal characteristics: emotional immaturity, low ability to display skills of adequate behavior; low level of communication skills and adaptation to the surrounding world; high level of anxiety and emotionality.

Thus, the data obtained as a result of the analysis confirm that the manifestation of posttraumatic stress disorders in high-class athletes have personal characteristics, depend on the individual psychological qualities and properties of the athlete, on the stability of the individual.

\section{References}

1. Yu.V. Shcherbatykh, Psychology of stress and methods of correction (Piter, St. Petersburg, 2011).

2. S.V. Cherbieva, S. N. Bostanova, Empirical study of stress resistance of young people, In: Formation of professional competence of a future specialist in the educational space of Russia, Materials of the IV International scientific and practical conference, KCSU, Karachayevsk 208-214 (2019).

3. Yu.V. Shcherbatykh, The use of methods of self-regulation and neuro-linguistic programming to reduce the level of stress in students, Prevention of offenses in the student environment (MODEK, Voronezh, 2010).

4. S.V. Cherbieva, S.N. Bostanova, On the question of the relationship between anxiety of the personality of youth and the consequences of stress, In: Materials of the scientific session, KCSU, Karachayevsk, 81-87 (2020)

5. S. Bostanova, F. Semenova, D. Akbaeva, Research of psychological support of the personality of the senior preschool child and his readiness for school in the conditions of transitive society, In: Trends in the Development of Psycho-Pedagogical Education in the Conditions of Transitional Society (ICTDPP-2019), EDP Sciences, Les Ulis. 08010 (2019) doi: https://doi.org/10.1051/shsconf/20197008010

6. L.Sh. Bostanova, A.S. Bogatyreva, D.D. Akbayeva, Scientists of the State University named after P. F. Lesgaft. 11(177), 494-499 (2019)

7. V.F. Sopov, Theory and methodology of psychological training in modern sports (Academic project, Moscow, 2010).

8. M.M. Ebzeev, F.O. Semenova, The role of information and communication technologies in the preparation of future specialists for professional activity in the process of training in higher education in modern conditions, In: Traditions and innovations in psychology and social work, Collection of scientific works, Karachayevsk, 139-143 (2019)

9. F.O. Semenova, I.V. Tkachenko, M.M. Ebzeev, J.B. Dodueva, A.O. Semenova, Psychological peculiarities of formation of university teacher's professional subculture, In: (ICPE 2019) International Conference on Psychology and Education, 599-604 (2019) doi: https://doi.org/10.15405/epsbs.2019.07.78

10. A.I. Akezheva, S.N. Bostanova, Emotional stress and ways to get out of a destructive state, In: Traditions and innovations in psychology and social work, Materials of the III All-Russian Scientific Practical Conference, KCSU, Karachayevsk, 7-14 (2020)

11. A.S.-M. Bijiev, Problems of modern pedagogical education 52(4), 254-261 (2016)

12. E.M. Kovsh, P.N. Ermakov, E.V. Vorobyeva, F.O. Semenova, O.I. Mikhaylenko, I.V. Abakumova, Behavior Genetics 49(6), 551 (2019) 
13. S.N. Bostanova, Zh.B. Dotdueva, The problem of recovery after stress during the pandemic, In: Traditions of innovation in psychology and social work, Materials of the III All-Russian Scientific Practical Conference, KCSU, Karachayevsk, 51-56 (2020)

14. F.O. Semenova, Problems of modern pedagogical education 53(4), 408-414 (2016)

15. F.O. Semenova, S.N. Bostanova, M.K. Tetuyeva, L.A. Apanasyuk, A.E. Ilyin, N.G. Atayanz, Formation peculiarities of students readiness to social self-determination, Man in India. 97(3), 77-87 (2017)

16. I.P. Volkov (Ed), Practicum on sports psychology (Piter, St. Petersburg, 2012).

17. M.M. Ebzeev, Training of employees of the branch "Physical culture and sport": ideas and solutions (monograph, Saint Petersburg, 2009).

17. L.Kh. Atchabaeva, A.S. Bogatyreva, Zh.B. Dotdueva, L.A. Bakhina, N.M. Adzhigaytarova, Scientists of the State University named after P. F. Lesgaft 11(189), 615-619 (2020) 